\title{
Book review : Communication and Social Change. A Citizen Perspective
}

\author{
Kivikuru, Ullamaija
}

2020-12-01

Kivikuru , U 2020 , ' Book review : Communication and Social Change. A Citizen Perspective

' , European Journal of Communication , vol. 35 , no. 6 , pp. 639-641 . https://doi.org/10.1177/0267323120965484

http://hdl.handle.net/10138/325295

https://doi.org/10.1177/0267323120965484

cc_by_nc_nd

acceptedVersion

Downloaded from Helda, University of Helsinki institutional repository.

This is an electronic reprint of the original article.

This reprint may differ from the original in pagination and typographic detail.

Please cite the original version. 


\section{Thomas Tufte}

Communication and Social Change. A Citizen Perspective. Polity Press: Cambridge, Malden, 2017; vi + ix +202 pp. € 21,20. ISBN: 9780745670386.

Reviewed by: Ullamaija Kivikuru, University of Helsinki, Finland

In his book, Communication and Social Change: A Citizen Perspective, Thomas Tufte has taken on quite a challenge: building a fresh argument from the myriad of research traits around communication and development that Silvio Waisbord (p. vii) has called an "intellectual smorgasbord" and that Tufte himself refers to as a "marathon." During the first flush of communication research in the 1950s and 1960s-the good old days of modernization-development communication belonged to the mainstream. However, when the world turned out to be far more complex and complicated than Wilbur Schramm, Everett Rogers, Daniel Lerner and others believed, this area of research was pushed into the margins of theoretical thinking. It soon became an ill-fitting jigsaw puzzle of aid programmes, campaigns, NGO activity, community dialogue, media criticism and digital technology plans.

Accordingly, Tufte's goal of developing a new grammar of change is timely. His book is one that deserves to be used as a textbook in the field as well as a refresher on existing ideas and perspectives. While it does not quite achieve its lofty aim of becoming a "paradigm and praxis in communication and social changes," as the author promises, it does open a kaleidoscope of fresh approaches and new perspectives.

Tufte constructs his argument about development, civic engagement and citizenship piece by piece. The structure of the book is interesting but requires concentrated reading. Tufte presents his key concepts, brings in new theoretical elements and then returns to those same concepts, building new aspects into them before moving on to a subsequent concept. Then, he returns to each, building one on top of the other to add new dimensions or details. The argument tends to become both loaded and fragmented.

In the introduction (Chapter I), the author focuses on subject and agency. This leads to a list of questions related to current scholars and practitioners, the use of conventional and digital media, communication practices within institutions such as the UN and NGOs, and, above all, social movements and civic engagement. Tufte also presents the classic model of the three generations of development communication and gives each his own twist. However, he does not start from a scholarly angle; instead, his text moves gradually from concrete case studies to more abstract considerations. While his lively descriptions of liberation pedagogy in Malawi, media activism in Brazil or HIV/AIDS prevention in subSaharan Africa support the elaboration of his argument, they also tend to point out its logical flaws.

The author divides the history of the field as most scholars do. His model contains conceptual approachesstarting with Rogers' diffusion of innovations model based on individual behaviour - then continues into a phase which Tufte calls "development of core life-skills," before ending with communication for social change, which for Tufte is strongly inspired by Paulo Freire's ideas. The writer provides an enlightening table which presents the similarities and differences between the different schools of thought concerning notions of culture, catalyst, education, audience and change. These differences then lead to different operational activities.

According to the writer, all three generations have common traits. All emerge from the institutionalised practice of communication, all tend to contain predefined goals and all are concerned with strategic communication. Further, a normative framing of development is easily detectable in all these models. These elaborations form the jumping-off point for an interesting argument about the contradictions 
between the pro-poor, pro-social approach embedded in the communication intent of all three generations and the neo-liberal elements found in the concept of development.

The next step (Chapter 2) describes changing contexts and central concepts, thus continuing the argument from the previous chapter. The focus is on social movements and their changing character. According to the text, development practice has transformed from service delivery to include an emphasis on democracy, human rights and advocacy. Tufte links the reclamation of the political angle to the rise in digital media. He points out the weaknesses of a variety of HIV/AIDS projects which have tried to change behaviour rather than push for profound social change, and the obvious lack of attention being paid to the citizen.

In this chapter, Tufte also refers to the debate around the New World Information and Communication Order (NWICO) and its emphasis on participation, but the discussion does not go much further. Instead, he introduces a number of researchers who have been important to his work. Tufte includes a wide range of interesting names from the Global South who are rarely mentioned in mainstream literature. His writing style when discussing his favourite authorities is eloquent and colloquial, but there is an occasional but distinct division of these thinkers both here and throughout the book into 'good' and 'not-so-good' groups. Alongside Freire, Tufte frequently refers to a range of southern voices, including Linje Manyozo, Mahmood Mamdani, Mohan Dutta, Jorge Gonzáles and Boaventura de Sousa Santos; he also introduces many others, primarily from Latin America. He does not include many names from the Global North, with notable exceptions being Nick Couldry, Colin Sparks and Peter Dahlgren.

Participation is the key concept in Chapter 3, which presents the diverse history, discourses and practices of participation. Tufte locates the start of participation in the late colonial years of the 1950s and 1960s. The paternalistic character of the early forms of mobilizing people for access to health and education follow the top/down modes of participation adopted by leaders of newly independent states. In the 1970s and 1980s, participation was linked with community work, echoing neoliberal development discourse. The 1990s signalled the first return of the political, with rights-based approaches and advocacy initiatives. A detailed description of a project from Porto Alegre, Brazil, supports Tufte's claim that participatory communication can serve as both service delivery and advocacy for a given cause.

One of the richest chapters of the book, Chapter 4 discusses movements, media and change. The text presents the newer concept of social movement theory, discusses Tufte's claim that ontological insecurity is a condition of life in the present day and talks about collective and connective action. Again, the writer's argument is strengthened by detailed case studies and analyses that are based on the theoretical concepts discussed in the chapter. Tufte points out that these cases led to new forms of organising discontent, as well as symbolic construction of public space based on a synergy between online and offline practices.

A movement toward global cognitive justice is the theme of Chapter 5. Tufte stresses the significance of the notion of cultures of governance as a core epistemological approach in development communication research and practice. He understands cultures of governance as the resources and dispositions that are in accordance with citizens' aspirations, that is, as the civic culture of a society. The concept remains abstract and slightly diffuse until it is framed in his case studies.

Two chapters (Chapters 6 and 7) focus on specific topics and tactics for development communication practice, the first emphasizing movements, the second discussing "invited spaces", i.e., UN agencies, NGOs and government institutions. Tufte is concerned about the growing corporatisation of social change and refers to the deeply critical opinions of Pradip Thomas, Karin Wilkins and Florencia Enghel in relation to this phenomenon. Special attention is given to UNICEF, which has recently changed its strategy and begun cooperating with social movements. 
In the concluding chapter (Chapter 8), Tufte ties together the dimensions for a new paradigm and praxis in communication and social change. After the strong mixture of theoretical considerations and practical applications presented in the previous chapters, the reflective tone of this concluding section allows the reader time to stop and think. However, his reflections are not totally convincing. The chapter is a summary rather than a synthesis of the elements presented earlier in the book - nevertheless, Tufte is heading in an interesting direction.

Tufte is a learned man. In this book, he is at his best in presenting detailed and analytical descriptions of case studies from the Global South, primarily from Africa and Latin America - and he himself participated in many of these projects. He provides lively descriptions of 'noisy' activism and 'silent' community work and then shoots down such stereotypes with incisive questions. He is not quite as successful when he addresses theoretical considerations. The idea of adding elements one by one to the concepts and phenomena he has already introduced does not always find success. The marathon is not yet over, but the finishing line is close. 